\title{
Uma Discussão da Questão Ambiental no Comércio Internacional
}

\author{
Rafaelle Gomes Firmino ${ }^{2}$ \\ Márcia Batista da Fonseca ${ }^{3}$
}

\section{RESUMO}

Este trabalho faz um levantamento acerca da Legislação Ambiental que vigora no Comércio Internacional e os prováveis efeitos da adoção dessas medidas na redução dos fluxos de comércio. O método e a forma de abordar o problema de pesquisa possuem natureza qualitativa, descritiva, de caráter exploratório, tendo como objetivo ampliar o conhecimento a respeito das questões referentes à legislação ambiental no comércio internacional. A pesquisa é de natureza bibliográfica e descreve a adoção de medidas restritivas ao comércio de acordo com as exigências ambientais, ou barreiras verdes, com relação às regras da OMC, utilizando como base as regras existentes no Acordo sobre Barreiras Técnicas ao Comércio (TBT) e no Acordo sobre a Aplicação de Medidas Sanitárias e Fitossanitárias (SPS). O Comitê sobre Comércio e Meio Ambiente (CTE) compatibiliza as regras do comércio mundial com os instrumentos de política ambiental, ficando ao seu cargo os Acordos Ambientais Multilaterais (MEAs). Os principais MEAs com efeito sobre o comércio são: Protocolo de Kyoto, o protocolo de Montreal, a convenção da Basiléia e o CITES. Percebe-se que a aprovação dos acordos multilaterais ambientais garante a conservação dos recursos naturais exauríveis, porém é importante que essas "barreiras verdes" não sejam usadas como uma forma de discriminação ao comércio ampliando o protecionismo.

Palavras-chave: Comércio Internacional. Legislação Ambiental. Desenvolvimento Sustentável.

\section{ABSTRACT}

This work makes a survey concerning the Ambient Legislation that invigorates in the International trade and the probable effect of the adoption of these measures in the reduction of the commerce flows. The method and the way of addressing the problem of research are qualitative, descriptive, exploratory, aiming to increase knowledge about issues of environmental law in international trade. The research literature is bibliographic and describes the adoption of restrictive measures to the commerce according to the ambient requirements or green barriers, with relation to the WTO rules, using as a base the existing rules in the Agreement on Techniques Barrier to Trades (TBT) and in the Agreement about the Application of Sanitary and Phytosanitary Measures (SPS). The Committee on Trade and Environment (CTE) makes compatible the rules of the worldwide trade with the instruments of ambient politics, being its position the Multilateral Environment Agreements (MEAs). Main the MEAs with effect on the commerce are: Kyoto's protocol, Montreal's protocol, the convention of Basiléia and CITES. We can notice that the approval of the ambient multilateral agreements guarantees the conservation of the exhaust natural resources, however is important that these "green barriers" are not used as a form of discrimination to the commerce extending protectionism.

Key Words: International trade. Ambient legislation. Sustainable development.

\section{INTRODUÇÃO}

Desde a Revolução industrial o planeta vem sofrendo com as transformações ambientais, causadas pela industrialização e por uma sociedade cada vez mais consumista. Esse avanço acelerado das características urbana e industrial vem agravando os impactos ambientais. O que gera a contaminação das águas, solo, o desmatamento, a piora do efeito estufa e a destruição da camada de ozônio, os quais são problemas que prejudicam não apenas uma nação, mas o mundo inteiro.

\footnotetext{
${ }^{1}$ Artigo recebido em 28.09.2011. Revisado por pares em 06.10.2011 (blind review). Reformulado em 01.11.2011. Recomendado para publicação em 15.11.2011 por José Ribamar Marques de Carvalho (Editor). Publicado em 01.12.2011. Organização responsável pelo periódico: UACC/UFCG.

Mestranda em Ciências Contábeis UnB/UFPB/UFRN e-mail: rafaelle1011@ hotmail.com

${ }^{3}$ Professora da UFPB, Doutorado em Economia - UFPE, Pós-Doutorado Ghent University (Bélgica). e-mail: mb_marcia@ hotmail.com
}

REUNIR - Revista de Administração, Contabilidade e Sustentabilidade - Vol. 1, nº 2, p.34-51, Set-Dez/2011. 
A alternativa de evitar uma catástrofe no planeta se dá através da interação internacional exigindo-se de cada país medidas de investimento e gastos do governo no sentido de mobilizar a população na defesa do meio ambiente. A preocupação de cada nação em manter a qualidade de vida da população, preservando a diversidade biológica ${ }^{4}$ de cada região, característica das propriedades fundamentais da natureza, responsável pela estabilidade e equilíbrio dos ecossistemas, e fonte de imenso potencial de uso econômico. Além disso, o uso da intervenção governamental com a utilização de políticas públicas atuando na área de conscientização dos agentes econômicos.

O impacto ambiental ocorre quando as pessoas usam recursos materiais e energéticos gerando resíduos que causam impactos negativos no ecossistema. Desta forma a política ambiental é de fundamental importância para alocar os devidos meios de controle para um desenvolvimento sustentável. Este é definido como àquele que atende as necessidades da geração presente sem comprometer as gerações futuras de atenderem as suas próprias necessidades, centrando-se em três eixos principais, tais como: crescimento econômico, equidade social e equilíbrio ecológico (MAY et. al. 2003).

May et. al. (2003) ressaltam que nas indústrias, os recursos naturais são transformados em matérias-primas e energia, gerando impactos ambientais iniciais tais como, desmatamento, emissões de gases poluentes, erosão de solos, entre outros. As matérias primas e a energia são os insumos da produção, que resultam no produto final e nos rejeitos industriais - fumaça, resíduos sólidos e efluentes líquidos. Sabe-se que os recursos naturais são finitos e muitas vezes não renováveis (minerais e fósseis) ${ }^{5}$, por isso, sua utilização deve ser racional a fim de que as gerações futuras também sejam beneficiadas pelos recursos naturais do planeta terra.

A Comissão Interministerial para preparação da conferência das Nações Unidas sobre Meio Ambiente e Desenvolvimento (1991) definiu que um dos problemas internacionais é o aquecimento da temperatura terrestre, o chamado "efeito estufa", provocado pela emissão de gases poluentes como dióxido de carbono (CO2), metano (CH4), óxidos nitrosos (NO2), ozônio (O3) e hidrocarbonetos halogenados (CFCS e halons). Dentre esses, têm-se a produção de energia a partir de combustíveis fósseis, responsáveis pelo aumento de $\mathrm{CO} 2$ e 5,5GtC/ano; atividades agropecuárias, relacionadas principalmente com o aumento de $\mathrm{CH} 4$ e $\mathrm{NO} 2$; produção e utilização de CFCS; desflorestamento, relacionado com a produção entre 0,4 e 2,6GtC/ano de $\mathrm{CO} 2$ (Giga toneladas de carbono) que contribuem para a concentração desses gases de forma mais intensa.

Conforme a Comissão Interministerial para preparação da conferência das Nações Unidas sobre Meio Ambiente e Desenvolvimento (1991), a concentração de CO2 na atmosfera é de $25 \%$ maior que na era pré-industrial. O metano, nos últimos três séculos, dobrou a sua concentração e aumenta a uma razão de $1 \%$ ao ano. Já o aumento do NO2 foi da ordem de 5 a $10 \%$ na atmosfera e um aumento anual da ordem de $0,25 \%$.

A partir do aumento das emissões de gases capazes de provocar alterações climáticas, a comunidade internacional passou a levar em consideração a necessidade do controle do nível de emissão desses gases relacionados com o "efeito estufa", com a aplicação urgente de medidas capazes de minimizar tais alterações.

\footnotetext{
4 Garay e B. Dias (orgs)(2001) entendem diversidade biológica coma a variabilidade de organismos vivos de todas as origens, compreendendo, dentre outros, os ecossistemas terrestres, marinhos e aquáticos e os complexos ecológicos de que fazem parte; além da diversidade dentro de espécies e de ecossistemas.A biodiversidade é responsável por atividades agrícolas, pecuárias ,pesqueira e florestais, além de base para a estratégica indústria da biotecnologia.

${ }^{5}$ May et al (2003) definem que os recursos naturais podem ser classificados em três tipos: os renováveis - fauna e flora - os não-renováveis - minerais e fósseis - e os livres - água, ar, luz solar e outros que existem em abundância.
} 
O Brasil produziu 10 mil toneladas de CFC em 1988 e 8,6 mil em 1990, enquanto os Estados Unidos produziu 280 mil toneladas em 1985, conforme a Comissão Interministerial (1991) foi quando se verificou, neste período, a existência de um buraco na camada de ozônio ${ }^{6}$ sobre a Antártica, o que provoca uma grande preocupação com a extensão horizontal deste buraco, já que poderia atingir regiões de maiores densidades populacionais.

Diante da crise ambiental atual tem-se um trade-off' entre dois elementos básicos: o crescimento e o meio ambiente. Assim, há um estilo de desenvolvimento internacional, que aparece nos processos de modernização da agricultura, de urbanização, de apropriação da base de recursos naturais e de utilização de fontes não renováveis de energia. Esse estilo é determinado, em grande parte, pelas empresas transnacionais.

Em 1972, na Conferência de Estocolmo ${ }^{8}$, expandia-se o conceito de que o mundo estaria entrando numa "economia do astronauta" em que com a deterioração ambiental não haveria mais uma fronteira para onde expandir as atividades econômicas da "economia de fronteira". A metáfora da economia do astronauta facilita demonstrar o caráter global e interdependente da sociedade de fins de século. Na conferência de Estocolmo se discutiu o impacto do crescimento econômico sobre o desenvolvimento social e o meio ambiente, ressaltando-se o uso dos escassos recursos naturais.

Desta forma, este trabalho tem o objetivo de apresentar a Legislação ambiental que vigora no comércio internacional e discutir o uso das barreiras verdes sobre a redução dos fluxos de comércio entre os países. Especificamente pretende-se fazer um levantamento de como as medidas de preservação ambiental interferem nas relações de comércio internacional; e descrever os procedimentos que estão sendo aprovados pela OMC nas Convenções, Tratados e Acordos Multilaterais entre os países que dizem respeito ao meio ambiente.

\section{FUNDAMENTAÇÃO TEÓRICA}

Dentro de uma perspectiva geral o meio ambiente passa a ser um conjunto de elementos físico-químicos, ecossistemas naturais e sociais em que o homem está inserido num processo de interação que atenda ao desenvolvimento das atividades humanas. May et. al. (2003) destacam que os recursos naturais utilizados nos processos industriais precisam ser utilizados de forma racional, sem comprometer as gerações futuras de atenderem as suas próprias necessidades.

Conforme a Lei ${ }^{\circ}$ 6938/81, artigo $3^{\circ}$, o meio ambiente é formado apenas pelos seus elementos naturais como também o conjunto de condições, leis, influências e interações de ordem física, química e biológica que permite, abriga e rege a vida em todas as suas formas. De acordo com o art. $5^{\circ}$, inciso LXXIII, da Constituição Federal (CF), em que o termo "natureza" abrange os reinos animal, vegetal e mineral, ficando excluídas de seu alcance propriedades humanas.

\footnotetext{
${ }^{6}$ Segundo a Comissão Interministerial para Preparação da Conferência das Nações Unidas sobre Meio Ambiente e Desenvolvimento (1991): O buraco de ozônio tem duas dimensões: a sua profundidade em UD ( Unidade Dobson) e sua extensão entre o pólo e o equador. Há dois cortes, em planos perpendiculares entre si, ambos centralizados no pólo Sul. O primeiro corte principia na interseção com o meridiano $0^{\circ} \mathrm{e}$ termina no $90^{\circ} \mathrm{W}$. Sabe-se que o buraco não é propriamente simétrico. E a sua influência já pode ser vista nas regiões próximas a $40^{\circ} / 45^{\circ}$, onde em várias longitudes o decréscimo da concentração de ozônio já representa 33\% do decréscimo máximo polar, chegando a parte setentrional do Chile e Argentina, na América do Sul, e também parte da Nova Zelândia, na Oceania.

${ }^{7} \mathrm{O}$ trade-off se configura na questão até que ponto o avanço tecnológico, a sociedade de consumo, modernização da agricultura, dentre outros, podem crescer sem prejudicar as fontes de recursos não-renováveis, já que há uma exploração dos recursos naturais.

${ }^{8}$ Declaração firmada por ocasião da Conferência das Nações Unidas, Estocolmo, Suécia, 5-15 de junho de 1972. Essa reunião colocou a questão ambiental na agenda mundial e detalhou a responsabilidade dos seres humanos na conservação do meio ambiente. Foi a primeira conferência em que houve uma importante declaração de princípios por parte de governos. Após concluir a conferência foi adotado um plano de ação na qual se traçavam metas de avaliação do impacto ambiental e de educação sobre a importância da conservação.
}

REUNIR - Revista de Administração, Contabilidade e Sustentabilidade - Vol. 1, nº 2, p.34-51, Set-Dez/2011. 
O tema deste século é a proteção ambiental, na CF de 1988, a questão do meio ambiente ganhou cara própria definindo os fundamentos da proteção ambiental. Esclarecendo a consciência humana da necessidade da convivência harmoniosa com a natureza, a Constituição Federal do Brasil representa um dos sistemas mais abrangentes e atuais do cenário internacional no aspecto ambiental.

Desde a conferência de Estocolmo de $1972^{\circ}$, o mundo passou a dar uma atenção especial ao meio ambiente. A legislação sobre a matéria tornou-se mais consistente, servindo como instrumento preventivo da degradação ambiental através da abertura do leque da conscientização humana sobre a preservação do ecossistema.

Desde a década de 1970 a economia do meio ambiente elaborou e aperfeiçoou um conjunto de métodos com o objetivo de determinar o preço que um bem público possui. É o chamado campo da valoração ambiental, sendo considerado como instrumento eficiente e consistente economicamente na sua forma de mensuração. Facilita descobrir de forma objetiva e consistente qual o preço de um bem público, por exemplo: quanto custa um ar puro?

O bem público é aquele que todos têm o direito de consumir na mesma quantidade. $\mathrm{O}$ bem público gera o problema do carona, pois se refere à tentação dos indivíduos de deixar que outras pessoas provejam os seus bens (VARIAN, 2001). Um exemplo simples é o da separação dos lixos orgânicos e inorgânicos nos lares, pois normalmente as famílias esperam que algum de seus membros se responsabilize pela separação do lixo, este mecanismo do carona, puramente individualista, não gera a quantidade ótima de um bem público.

Segundo Varian (2001) a principal característica de externalidade é que há bens com os quais as pessoas se importam e que não são vendidos nos mercados. Não há mercado para emissão de poluentes produzidos por uma indústria, é a falta desse mercado que causa problemas. Tais externalidades caracterizam-se como sendo os efeitos das atividades de produção e consumo que não se refletem diretamente no mercado, quando o comportamento de um agente econômico exerce impacto sobre outro, e este impacto não tem preço no mercado.

\subsection{A Questão Ambiental no Comércio Internacional}

Os países utilizam barreiras não tarifárias para restringir à entrada de mercadorias importadas como base em requisitos técnicos, sanitários, ambientais, laborais, restrições quantitativas (quotas e contingenciamento de importação), assim como políticas de valoração aduaneira, de preços mínimos e de bandas de preços.

May et. al. (2003) dizem que a política ambiental de diferentes países pode influenciar nos fluxos de comércio internacional. Quando o produto ou o seu método de produção causam problemas ambientais, o país importador pode colocar barreiras ao comércio internacional. Estas são as barreiras não tarifárias, também conhecidas por barreiras verdes. Restringe-se, desta maneira, o comércio internacional com o objetivo de proteger o meio ambiente. Quando os países importadores impõem as barreiras verdes, o país exportador reduz a produção industrial, diminuindo a renda e o emprego gerados pela indústria.

Um exemplo de restrição comercial internacional baseada na regulamentação ambiental ocorre quando os Estados Unidos (EUA) proibiram a importação da gasolina brasileira e venezuelana em 1995. A agência ambiental norte-americana (EPA) estabeleceu a Regra da gasolina (gasoline Rule), ou seja, impôs padrões de qualidade para a gasolina

\footnotetext{
${ }^{9}$ Segundo a Comissão Interministerial para Preparação da Conferência das Nações Unidas sobre Meio Ambiente e Desenvolvimento (1991).
}

REUNIR - Revista de Administração, Contabilidade e Sustentabilidade - Vol. 1, n ${ }^{\circ}$ 2, p.34-51, Set-Dez/2011. 
utilizada pelos consumidores norte-americanos. A exigência era de que apenas gasolina com especificação determinada teria permissão para ser vendida nas áreas mais poluídas e a gasolina convencional no restante do país, cujo padrão não poderia ser mais sujo do que do ano-base 1990 (MAY et. al. 2003).

Entretanto, para as refinarias norte-americanas que já operavam em 1990 foi estabelecido um patamar mínimo individual com base no patamar mínimo de poluição de 1990. Desta forma, os padrões de qualidade para as refinarias domésticas poderiam ser inferiores para a gasolina importada. O Brasil e a Venezuela recorreram ao Acordo Geral de Tarifas e Comércio (GATT) e a Organização Mundial de Comércio (OMC), os EUA perderam em todas as instâncias julgadas no GATT/OMC, assim, os Estados Unidos foram obrigados a voltar atrás e retirar as restrições às gasolinas estrangeiras. Logo, tal prática configura-se em uma restrição ao comércio e não uma medida de proteção ambiental.

\subsection{Barreiras não tarifárias ao Comércio Internacional}

As barreiras não tarifárias (BNTs) têm o objetivo de proteger bens jurídicos importantes para os Estados, como a segurança nacional, a proteção do meio ambiente e do consumidor, além da saúde dos animais e das plantas. Contudo, é exatamente o fato de os países usarem medidas ou exigências sem que tenham fundamentos claros que as fortaleçam, que da origem às barreiras não tarifárias ao comércio, formando o que se chama de neoprotecionismo. Conforme estabelece a Organização Mundial do Comércio (2011), as BNTs classificam-se em: (i) quotas e contingenciamento de importação; (ii) barreiras técnicas; (iii) medidas sanitárias e fitossanitárias e (iv) exigências ambientais e laborais.

$\mathrm{Na}$ atualidade, as barreiras não tarifárias, que são as barreiras técnicas, têm importância como mecanismo de proteção aos mercados. Essas barreiras afetam as exportações de países em desenvolvimento, pois os fabricantes desses países têm menor capacidade tecnológica, desta forma, dificulta o cumprimento das exigências técnicas.

Segundo as regras estipuladas pela $\mathrm{OMC}$, as barreiras técnicas às exportações são as barreiras comerciais oriundas da utilização de normas ou regulamentos técnicos não transparentes ou que não se baseiam em normas internacionalmente aceitas. As normas e os regulamentos técnicos são entendidos como os documentos que estabelecem características do produto, como função, desempenho, embalagem, etiquetagem, ou métodos e processos de produção relacionados, as normas são de caráter voluntário e o regulamento de caráter compulsório.

Com a intensificação do processo de globalização da economia mundial, e conseqüentemente o aumento do fluxo de comércio internacional, as barreiras tarifárias foram sendo substituídas por um tipo particular de barreiras não tarifárias. Os países desenvolvidos passam a impor barreiras não tarifárias ambientais, as conhecidas barreiras verdes, atribuindo aos países em desenvolvimento leis ambientais menos rígidas que as suas, resultando em custos mais baixos a produção, consequentemente, menores preços no mercado internacional.

Tal prática visa apenas o comércio, pois os países em desenvolvimento com leis ambientais menos rígidas no seu processo de produção, gera custos menores no curto prazo devido não tomar as medidas de conservação e manutenção do meio ambiente, porém no longo prazo os impactos negativos causados pela falta de cuidado e prevenção ambiental serão imensuráveis.

Entretanto, os novos padrões de gestão ambiental estão baseados no ciclo de vida dos produtos desde a sua extração, método e processo de produção até os despojos dos restos no processo de produção, como também, o descarte dos produtos no seu ciclo final de consumo.

REUNIR - Revista de Administração, Contabilidade e Sustentabilidade - Vol. 1, nº 2, p.34-51, Set-Dez/2011. 


\subsection{Os problemas Ambientais Causados pelo Comércio Internacional}

Os casos mais comuns de problemas ambientais causados pelo comércio internacional estão caracterizados como: Danos ambientais provocados pelo transporte de mercadorias de um país para outro. Emissões atmosféricas oriundas do transporte internacional de mercadorias e os possíveis acidentes podem contaminar o meio ambiente. O efeito ambiental líquido do aumento dos fluxos de comércio internacional depende das modificações do padrão desse comércio, dos parceiros comerciais e do tipo de mercadoria exportada, além de políticas que estimulem determinados tipos de transportes menos poluentes.

Os processos e métodos de produção (PPMs) são as formas pelas quais um produto é elaborado. Quais ingredientes, aditivos, equipamentos e materiais são utilizados na sua composição. A forma como o produto foi produzido pode causar danos ambientais no próprio país produtor ou em outros países. Assim, os danos ambientais advindos de PPMs podem ser: poluição transfronteiriça - ocorre quando há poluição do ar ou dos recursos hídricos comuns.

Por exemplo, a emissão de dióxido de enxofre (SO2) em um país pode provocar chuva ácida em outro. Espécies migratórias e recursos vivos comuns são ameaçados de extinção quando são praticados PPMs agressivos ao meio ambiente. São exemplos as ameaças de extinção de espécies aquáticas devido a métodos de pesca inadequado. As tartarugas marinhas sofreram essa ameaça. E preocupações com o meio ambiente global - aparecem quando os PPMs prejudicam recursos comuns a todos os países. Alguns exemplos são: os impactos negativos causados na camada de ozônio pelo uso de gases do tipo clorofluorcarbono (CFC); as alterações climáticas provocadas pela derrubada e queimadas de florestas tropicais nativas, conseqüência da extração irracional de madeiras e sem reposição da biomassa; ou o aquecimento global que é consequência da alta concentração de dióxido de carbono (CO2) na atmosfera, dentre outros, provocados pela queima de combustíveis fósseis.

\subsection{A Organização Mundial do Comércio (OMC) e a Questão Ambiental}

A OMC é uma organização internacional que tem como objetivo garantir o cumprimento dos acordos sobre as regras do comércio entre os estados-membros 150/165 e serve de foro para as negociações de novas regras ou temas relacionados ao comércio. A OMC segue princípios de 1947, estes criados no âmbito da GATT (Acordo Geral de Tarifas e Comércio), o qual possuía como objetivo primordial assegurar a previsibilidade nas relações comerciais internacionais e um processo contínuo de liberalização do comércio.

\subsubsection{As Regras da Organização Mundial do Comércio Relativas ao Ambiente}

Estes são os princípios que regem a OMC (2011) e há uma paridade com relação ao meio ambiente: O Artigo I - Princípio da nação mais favorecida - Estabelece que todos os países membros necessitam ter igual tratamento, não se deve favorecer um dos membros em detrimento dos outros. Ou seja, se um membro criar condições que melhorem os bens e serviços de outro, então deve estabelecer igual tratamento para o restante dos membros.

Artigo III - Principio do tratamento nacional - Estabelece que os produtos importados devam ser tratados da mesma forma que os produtos domésticos, o país não podendo criar condições que favoreçam os produtos domésticos e prejudiquem os importados. Este princípio não faz sentido em termos ambientais, já que considera como iguais os produtos que têm o mesmo uso final e as mesmas características independentemente do seu processo de

REUNIR - Revista de Administração, Contabilidade e Sustentabilidade - Vol. 1, nº 2, p.34-51, Set-Dez/2011. 
fabricação, que não deve ser esquecido, pois a preocupação deve ser desde a extração até o consumo final do produto e não apenas a natureza do mesmo.

Artigo XX - As exceções relativas ao Ambiente - Ou seja, se um país entende que as suas importações prejudicam ao ambiente ou à saúde humana, este cria medidas que limitem as mesmas. Com isso, são permitidas exceções aos artigos I e III estabelecidos pela OMC (2011), contanto que estas sejam necessárias a proteção da saúde humana, animais e plantas ou ainda relacionadas com a proteção das fontes naturais esgotáveis. Entretanto, as medidas tomadas no âmbito do artigo XX da OMC não devem constituir uma forma arbitrária de discriminação ou de discriminação injustificável.

\subsubsection{As Exigências Ambientais e as Regras da OMC}

As exigências ambientais com relação às regras da OMC surgem com a alternativa de adoção de medidas restritivas ao comércio que utilizem como base o artigo XX do GATT, alíneas "b" e "g", assim como as regras existentes no Acordo sobre Barreiras Técnicas ao Comércio (TBT) e no Acordo sobre a Aplicação de Medidas Sanitárias e Fitossanitárias (SPS). Essas medidas restritivas ao comércio têm o objetivo de: (i) proteger a vida e a saúde humana, animal e vegetal, e (ii) cuidar da conservação dos recursos naturais exauríveis. A execução de medidas com base nessas exceções não deve servir como uma forma de discriminação arbitrária ou injustificável, evitando-se que se transforme em protecionismo.

Tem-se o princípio da não discriminação que está refletido em duas cláusulas - a da Nação Mais Favorecida (NMF) e a do Tratamento Nacional. A primeira determina que qualquer vantagem, privilégio ou imunidade, garantida a qualquer parte contratante do acordo, independente de qual seja o produto, deve ser estendida as outras partes contratantes.

Já a cláusula do Tratamento Nacional estabelece que produtos importados de países contratantes não possam ser submetidos a impostos internos ou outros tipos de encargos, que sejam superiores aos aplicados direta ou indiretamente aos produtos domésticos.

A Organização Mundial do Comércio (OMC) tem como objetivo garantir o cumprimento dos acordos e regras sobre o comércio. Para evitar conflito entre o comércio e o meio ambiente criou-se o Comitê sobre Comércio e Meio Ambiente que tem a seu cargo a compatibilização das regras do comércio mundial e os instrumentos de proteção ambiental.

\subsubsection{Acordo sobre Barreiras Técnicas ao Comércio (TBT)}

O acordo sobre barreiras técnicas, o TBT, estabelece que os regulamentos e as normas técnicas não devem ser mais restritivos ao comércio do que o necessário para atingir os seguintes fins: segurança nacional, prevenção de práticas enganosas, proteção a saúde ou segurança humana, vida e saúde animal e vegetal, e meio ambiente. Para verificar os riscos devem ser consideradas as informações técnicas e científicas disponíveis, tecnologias de processamento e a destinação final dos produtos.

As provisões do TBT são de cumprimento obrigatório para todos os membros da OMC. Suas disposições definem que os responsáveis pela adesão não devem produzir exigências técnicas, como normas, regulamentos técnicos e procedimentos de avaliação da conformidade, que criem obstáculos ou barreiras técnicas ao comércio. O TBT tem como um de seus objetivos a harmonização das exigências técnicas entre os países membros. Estimulase a sua elaboração com base em normas internacionais e incentiva-se a participação de tais países em organizações internacionais de normatização. 
Com o objetivo de alcançar a transparência nos processos de elaboração de regulamentos técnicos e procedimentos de avaliação da conformidade, os países-membros devem estabelecer centros de informação ou pontos focais.

No Brasil, o centro de informação de exigências técnicas é de responsabilidade do Instituto Nacional de Metrologia e Qualidade Industrial (INMETRO), este presta informações sobre qualquer regulamento ou proposta de regulamento. Esses centros de informação devem responder a todas as consultas razoáveis de outros membros e de partes interessadas de outros membros, assim como disponibilizar os documentos cabíveis a regulamentação técnica e aos procedimentos de avaliação de conformidade.

\subsubsection{Acordo sobre a Aplicação de Medidas Sanitárias e Fitossanitárias (SPS)}

O acordo SPS, que trata de barreiras técnicas no âmbito da OMC, foi assinado em 1994, como parte das negociações da Rodada Uruguai do antigo GATT, e regula a aplicação das medidas sanitárias e fitossanitárias no comércio multilateral. Este acordo legitima exceções ao livre comércio, as quais podem ser utilizadas pelos Membros da OMC quando houver necessidade de proteger a vida e a saúde humana, animal e vegetal.

O SPS visa impedir que medidas que objetive a proteção a saúde das pessoas, plantas e animais constituam barreiras ao comércio internacional, estimulando a harmonização destas medidas no âmbito internacional. $\mathrm{O}$ acordo tem o objetivo de impedir que os países emitam medidas de forma discricionária, com o intuito de criar barreiras ao comércio, pois estabelece que sejam atestadas cientificamente a necessidade de adotar ou manter tal medida.

Nas provisões do SPS está presente o princípio da não discriminação, pois um país não deve exigir o cumprimento de uma medida que não seja estendida aos produtores nacionais. $\mathrm{O}$ SPS também estipula que sejam criados centros de informação ou ponto focal em cada paísmembro participante do acordo, responsabilizando-se de informar aos demais a existência de medidas sanitárias e fitossanitárias ${ }^{10}$.

\subsection{O Comitê sobre Comércio e Meio Ambiente (CTE)}

A preocupação de estabelecer regras que evitem o conflito entre o comércio e meio ambiente levou à criação de organismos que se dedicam a esta questão, como é o caso do Comitê sobre Comércio e Meio Ambiente - CTE, criado em 1994 dentro da OMC. Este tem ao seu cargo, a compatibilização das regras do comércio mundial e os instrumentos de proteção ambiental, como por exemplo, os acordos ambientais multilaterais, os esquemas de rótulos ecológicos e o Princípio da Precaução.

A OMC é uma instituição com capacidade para tratar das questões relacionadas ao comércio internacional e não propriamente ao meio ambiente. Isto quer dizer que, em matéria de política ambiental, sua missão é estudar os impactos que surgem no campo comercial advindos da aplicação de tais políticas. E uma vez surgindo problemas ambientais, as soluções devem ser tomadas seguindo os princípios do sistema de comércio internacional definidos na OMC.

Os ambientalistas defendem a ideia de que a liberalização do comércio, argumentada pela OMC, degrada o meio ambiente e é incompatível com o ideal de desenvolvimento

\footnotetext{
${ }^{10}$ INMETRO (2006) entende que as medidas sanitárias são barreiras não tarifárias que têm o objetivo de proteger a vida e a saúde humana e animal dos riscos advindos de aditivos, contaminantes, tóxicos, agrotóxicos, doenças, pestes e organismos causadores de doenças vindos de alimentos, bebidas ou suprimentos alimentares ( exemplo da proteção dos rebanhos de gado contra a possibilidade do animal adquirir a vaca louca). Uma medida fitossanitária também é uma barreira técnica que visa proteger os vegetais (plantas e frutas) de doenças e pestes.
}

REUNIR - Revista de Administração, Contabilidade e Sustentabilidade - Vol. 1, n ${ }^{\circ}$ 2, p.34-51, Set-Dez/2011. 
sustentável. Entretanto, os defensores do livre-comércio temem que as regras ambientais possam ser utilizadas como justificativa para o protecionismo principalmente pelos países desenvolvidos.

Os principais tratados ambientais com efeito sobre o comércio são: o Protocolo de Kyoto, o Protocolo de Montreal, que dispõe sobre proteção à camada de ozônio, a Convenção da Basiléia, que trata do transporte e comércio transfronteiriço de resíduos perigosos, e a Convenção sobre o Comércio Internacional de Espécies da Fauna e da Flora Selvagens em Perigo de Extinção (CITES).

\section{METODOLOGIA DA PESQUISA}

O método e à forma de abordar o problema de pesquisa são de natureza qualitativa, pois se fundamenta na análise que tem por base o conhecimento teórico-empírico, o que permite atribuir-lhe cientificidade (ZANELLA, 2009).

Gil (1990) classifica as pesquisas, quanto aos fins, em três grandes grupos: exploratórias, descritivas e explicativas. A pesquisa aqui realizada classifica-se, quanto aos fins como sendo descritiva. A pesquisa descritiva expõe características de determinada população ou de determinado fenômeno. Neste caso a preocupação refere-se ao ambiente em que se manifesta, em conhecer os acordos, normas e convenções ambientais que vigoram no comércio internacional, através das chamadas barreiras verdes.

Quanto aos objetivos da pesquisa, esta se caracteriza como exploratória, já que tem o interesse em ampliar o conhecimento a respeito das questões ambientais no comércio internacional para se obter um desenvolvimento sustentável.

Para Gil (1990) a pesquisa bibliográfica é desenvolvida a partir de material já elaborado, constituído principalmente de livros e artigos científicos. Este trabalho tem aspecto bibliográfico, já que é realizada através de: livros, artigos científicos, jornais, revistas, informações colhidas na Internet, institutos de pesquisa etc.

\section{ANÁLISE E DISCUSSÃO DOS RESULTADOS}

Esta seção será destinada a tratar os aspectos relacionados às questões ambientais no comércio internacional, as barreiras não tarifárias, também conhecidas como barreiras verdes. Tratará dos aspectos relacionados a legislação ambiental no comércio internacional.

Há aproximadamente 20 acordos ambientais multilaterais relacionados com a restrição do comércio, o que permite aos países restringir a importação de determinados produtos. Serão detalhados os principais tratados e convenções com maior impacto sobre o fluxo de comércio.

\subsection{Acordos Ambientais Multilaterais}

Abreu (2011) diz que devido a dimensão geográfica dos problemas ambientais, os acordos ambientais multilaterais surgiram como forma de lidar com essas questões a nível internacional. Os tratados e as convenções multilaterais, quando negociados sob a égide de uma organização internacional, seguem princípios por ela estabelecidos. Normalmente, são específicos quanto à entrada em vigor, o processo de ratificação ou adesão e estabelecem referências ao depositário e à possibilidade de se efetuarem reservas.

A União Européia - UE (principal negociante da OMC sobre questões ambientais), contando com o apoio do Japão, Noruega e Suíça, trabalhou para que as questões ambientais

REUNIR - Revista de Administração, Contabilidade e Sustentabilidade - Vol. 1, nº 2, p.34-51, Set-Dez/2011. 
fossem incluídas na Declaração Ministerial de Doha ${ }^{11}$. Embora, os demais componentes da OMC fossem contrários a essas negociações. Os questionamentos dos países em desenvolvimento ocorrem devido ao desejo de focar a agenda para questões urgentes ligadas ao desenvolvimento.

Esses países temiam que as negociações sobre o meio ambiente pudessem fortalecer o uso de medidas ambientais para restringir o acesso a mercados, prejudicando seus próprios produtos. Já, os EUA, mais alguns países membros do grupo Cairns ${ }^{12}$, países exportadores de produtos agrícolas, preocupavam-se com o potencial da UE de utilizar um acordo multilateral para alavancar as reformas sobre subsídios agrícolas, ou então para restringir ou diminuir a entrada de produtos agrícolas transgênicos ${ }^{13}$. Esta restrição poderia ser feita por meio de rotulagem ou então invocando a necessidade de medidas de precaução o que prejudicaria os produtores desses produtos.

Os Ministros do Grupo Cairns enfatizaram na XXIII Reunião Ministerial, em Doha, Catar-9 de novembro de 2001, a importância da reforma agrícola para o futuro sistema de trocas entre nações. O grupo Cairns, do qual o Brasil faz parte, dentre outros, incluindo Austrália, a Argentina e o Canadá, defende uma negociação para a redução gradual dos subsídios à exportação de produtos agrícolas em países desenvolvidos, com o objetivo de eliminar estes subsídios completamente.

A relação entre os Acordos Multilaterais de Meio Ambiente (MEAs) e a OMC encontra-se centrada em questões procedimentais. Países como EUA, Canadá, Austrália, Argentina, Índia e Malásia desejariam manter o mandato o máximo restrito, centralizando as discussões em um número limitado de Acordos Multilaterais e em suas obrigações comerciais específicas, obrigatórias e explícitas. Existem cerca de 200 acordos multilaterais para a proteção do ambiente. Desses acordos, aproximadamente 20 incluem medidas relacionadas com a restrição do comércio, permitindo os países restringir a importação de determinados produtos (ABREU, 2011).

Essas disposições são legais à luz das regras da OMC, que impossibilitam a tomada de decisões e limitam as trocas comerciais, até o ponto que tais disposições não se choquem com as regras da $\mathrm{OMC}$, que preconiza que todos os parceiros devem ter igual tratamento. Um bom exemplo é o protocolo de Kyoto que preconiza a criação de um mercado de emissões de certificados para os países participantes, excluir os membros desse mercado que não assinaram o protocolo contrariará as regras da OMC, que defende a ideia de que todos os parceiros comerciais devem obter o mesmo tratamento.

\subsubsection{Protocolo de Kyoto}

O protocolo de Kyoto constitui-se em um tratado internacional com compromissos mais rígidos para a diminuição da emissão dos gases que provocam o efeito estufa que, de acordo com as investigações científicas, é a causa do aquecimento global.

Em 1997, na cidade Japonesa de Kyoto, foi assinado o protocolo de Kyoto contendo um acordo que compromete uma série de nações desenvolvidas a reduzirem suas emissões de CO2 em 5,2\%, em relação aos níveis de 1990 para o período de 2008 a 2012. Terminou em

\footnotetext{
${ }^{11}$ A Declaração Ministerial de Doha (DMD) começou em 2001, foi a IV Conferência Ministerial da Organização Mundial do Comércio.

${ }^{12}$ O grupo Cairns foi constituído em 1986 - em Cairns, Austrália, para influenciar as negociações da área agrícola, na OMC. Este grupo inclui grandes exportadores de produtos agrícolas tanto de países desenvolvidos quanto em desenvolvimento como a Argentina, Austrália, Brasil, Canadá, Chile, Colômbia, Filipinas, Hungria, Indonésia, Malásia, Nova Zelândia, Tailândia e Uruguai (ABREU, 2011).

${ }^{13}$ Os produtos agrícolas transgênicos são organismos geneticamente modificados (organismos geneticamente modificados-OGM) que recebem material genético recombinante de organismos de outras espécies. Os OGM sofrem alteração no seu código genético por métodos ou meios que não ocorrem naturalmente.
}

REUNIR - Revista de Administração, Contabilidade e Sustentabilidade - Vol. 1, nº 2, p.34-51, Set-Dez/2011. 
maio de 2006, a reunião realizada em Bonn, na Alemanha, sobre o Protocolo de Kyoto, com a presença de representantes de 160 países. O Protocolo que obriga as 35 nações mais desenvolvidas a reduzirem a emissão de $\mathrm{CO} 2$, embora sem a adesão dos Estados Unidos (GREENPEACE, 2011).

Fala-se, agora, sobre os novos cortes para a segunda fase do Protocolo, a partir de 2012, pretendendo-se reduzir as diferentes posições entre combater o aquecimento global e os impactos econômicos da medida. $\mathrm{O}$ protocolo incentiva os países signatários a reduzirem as emissões de gases que provocam o efeito estufa, através de algumas ações básicas em várias atividades econômicas, tais como: reforma dos setores de energia e transportes; incentivo ao uso de fontes energéticas renováveis; exclusão dos mecanismos financeiros e de mercados impróprios aos objetivos da Convenção; estipular os limites de emissão de metano no gerenciamento de resíduos e dos sistemas energéticos; proteção a florestas e outros sumidouros de carbono.

Os Estados Unidos negaram-se a assinar o protocolo de Kyoto, o presidente americano George W. Bush alegou que os compromissos oriundos do protocolo interfeririam negativamente na economia norte-americana. Além de questionar o consenso científico de que os poluentes emitidos causem a elevação da temperatura global. Entretanto, alguns municípios, Estados (Califórnia) e proprietários de indústrias do nordeste americano já iniciaram pesquisas com objetivos de reduzir a emissão de gases tóxicos, de forma a não diminuir sua margem de lucro com essa atitude.

Em junho de 2001 na Alemanha, o Protocolo de Kyoto abrandou o cumprimento das metas previstas anteriormente, por meio dos "sumidouros de carbono". Assim os países que tivessem grandes reservas florestais, que absorvem naturalmente o $\mathrm{CO} 2$, poderiam usar essas florestas como crédito em troca do controle de suas emissões. Os países desenvolvidos são os maiores emissores de $\mathrm{CO} 2$ e de outros poluentes, por isso, para manter sua produção industrial poderiam transferir parte da sua indústria mais poluente para os países onde o nível de emissão é baixo ou investir nesses países como parte da negociação.

O Protocolo de Kyoto, caso entre em vigor, pode causar vários impactos sobre o comércio: o comércio de créditos de emissão de carbono: mesmo que a comercialização dos direitos de emissão se dê entre os países, é possível que o direito de emissão seja transferido a determinadas indústrias dómesticas, desta forma, configura-se como uma forma de subsídio; caso os subsídios fossem utilizados em um setor específico com o objetivo de diminuir o efeito poluidor da indústria beneficiada, seria necessário regras bem definidas para evitar que se tornasse um mecanismo distorcivo ao comércio; a imposição de uma taxa sobre a emissão de dióxido de carbono, afetando a produção de bens que exigem grande quantidade de energia, poderia afetar negativamente a competitividade do produtor doméstico em relação aos produtores de outros países que não estivessem sujeitos a essa taxa; definir padrões ambientais estritos, em tese não proibidos pelas regras da OMC, poderia gerar problemas de competitividade do produto nacional em comparação ao estrangeiro ou vice-versa em relação ao produto estrangeiro.

\subsubsection{Protocolo de Montreal}

Este protocolo foi elaborado em 16 de setembro de 1987, está depositado junto ao Secretário- Geral da Organização das Nações Unidas (Kofi Annan). O Protocolo de Montreal foi subscrito em 1987 e atualmente aproximadamente 180 nações estão comprometidas em atingir as metas de redução de gases CFC (clorofluorocarbono), halons e brometo de metilo, cuja presença na atmosfera é apontada como a principal causa do estreitamento da camada de

REUNIR - Revista de Administração, Contabilidade e Sustentabilidade - Vol. 1, nº 2, p.34-51, Set-Dez/2011. 
ozônio. Este problema só começou a ser conhecido da opinião pública na década de 80 , em 1983 foi subscrito o Convênio de Viena, como o primeiro instrumento destinado a criar medidas para a proteção do ozônio, apenas 20 países participaram.

O estreitamento da camada de ozônio impede a filtragem adequada dos raios ultravioletas, causando problemas para a vida no planeta terra. O Protocolo de Montreal entrou em vigor em 1989, quando 29 países juntamente com a União Européia, produtores de 89\% das substâncias nocivas à camada de ozônio, o ratificaram (PNUMA, 2000).

O Protocolo gerou além de uma Secretaria do Ozônio do Programa das Nações Unidas para o Meio Ambiente (PNUMA), um Fundo Multilateral para ajudar países em desenvolvimento na substituição tecnológica necessária para deixar de usar produtos que prejudicam a camada de ozônio. O Programa das Nações Unidas para o Desenvolvimento (PNUD) e o Banco Mundial com projetos que visam o mesmo alvo: O cumprimento do disposto no Protocolo de Montreal.

Os países presentes neste Protocolo, em virtude da convenção de Viena para a proteção da Camada de Ozônio adotada em março de 1985, são conscientes das suas obrigações de adotar medidas cabíveis para proteger a saúde do homem e do ambiente contra os efeitos nocivos que resultam ou podem resultar de atividades humanas que modificam a camada de ozônio.

As emissões de certas substâncias em todo o mundo podem modificar e deteriorar consideravelmente a camada de ozônio de modo que podem ocorrer repercussões nocivas na saúde humana e no meio ambiente; as emissões destas substâncias têm potenciais efeitos climáticos. Por isso, é de fundamental importância que as medidas que visem proteger o ambiente sejam dotadas de fundamentação científica, levando em conta aspectos técnicos e econômicos.

As medidas são determinadas a proteger a camada de ozônio, com caráter preventivo para regulamentar eqüitativamente o total das emissões mundiais de substâncias que a deterioram, com o objetivo final de eliminá-las, através da evolução dos conhecimentos científicos, tendo em conta aspectos técnicos e econômicos.

Há de se tomar medidas especiais para satisfazer as necessidades dos países em vias de desenvolvimento, constatando que já foram tomadas medidas preventivas em escala nacional e regional para regulamentar as emissões de certos clorofluorocarbonos.

Este protocolo tem por objetivo que os principais países produtores de substâncias nocivas à saúde do homem e do meio ambiente adotem a execução de medidas básicas de proteção em várias atividades da economia, tais como: reforma dos setores de energia e transportes; exclusão de mecanismos financeiros e de mercados impróprios aos objetivos da convenção; determinação de limites de emissão de gases CFC nas indústrias, dentre outras ações.

Os países desenvolvidos são os maiores poluidores de CFC, por isso, para manter a sua produção industrial e cumprir o acordo poderiam transferir para outros países parte da sua indústria mais poluente ou, até mesmo, investir nesses países como parte da negociação. Ou, devido aos padrões ambientais estritos aos países presentes no protocolo, estes poderiam alterar a competitividade do produto nacional em relação ao produto estrangeiro.

\subsubsection{Convenção sobre o Comércio Internacional de Espécies da Flora e Fauna Selvagens em Perigo de Extinção - CITES}

A CITES é um dos acordos ambientais mais relevantes para preservação das espécies, tendo grande parte dos países do mundo como signatários. Foi criada devido ao grande 
volume de animais e plantas silvestres comercializados internacionalmente e também devido a destruição de habitats que podem reduzir as populações até o ponto de risco de sobrevivência das espécies.

A convenção regulamenta a exportação, reexportação e importação de animais e plantas, suas partes e derivados, por meio de um sistema de certificados que são expedidos quando se cumprem alguns requisitos. Um dos requisitos é se determinado tipo de comércio prejudicará ou não a sobrevivência da espécie. Há um comércio bastante diversificado, desde os animais até as plantas há uma vasta gama de produtos derivados, como produtos alimentícios, artigos de couro, de animais exóticos, instrumentos musicais fabricados com madeiras, dentre outros.

$\mathrm{Na} 7^{\mathrm{a}}$ Assembléia Geral da União Internacional para a Conservação da Natureza e seus Recursos Naturais (UICN), em 1960, conclamou-se aos governos para limitar suas importações de animais em consonância com as regulamentações de exportação dos países de origem. Porém, não havia nenhum acordo formal que permitisse aos países importadores conhecerem os regulamentos dos países exportadores. Em 3 de março de 1973, numa reunião com representantes de 80 países celebrada em Washington, Estados Unidos da América, subscreveu a convenção sobre o Comércio Internacional de Espécies da Flora e Fauna Selvagens em Perigo de Extinção - CITES, que entrou em vigor em $1^{\circ}$ de julho de 1975 (CITES, 2011).

Os Estados que aderem à Convenção são conhecidos como partes. Pois estão obrigados a aplicar as normas da CITES, porém não são superiores as legislações nacionais.

Todavia, oferece um modelo que deve ser respeitado por cada um dos signatários, que devem promulgar sua própria legislação nacional para garantir a aplicabilidade da convenção em escala nacional.

O Brasil é um dos poucos países em desenvolvimento que possui legislação própria, permitindo que a utilização da CITES permeie normas que regulamentam o manejo da fauna e da flora silvestre. Pelo Decreto Legislativo (DL) 54 de 24 de junho de 1975 e promulgada pelo Decreto 76.6233 de 17 de novembro de 1975, sendo alterada pelo DL 35 de 5 de dezembro de 1985 e promulgada pelo DL 92.446 de 7 de março de 1986 (CITES, 2011).

As espécies de animais amparadas pela CITES são em torno de 5000 e 28000 espécies de plantas amparadas contra a exploração excessiva devido ao Comércio Internacional. Atualmente são 169 partes que aderiram à Convenção.

A aplicação das normas da CITES causa uma redução significativa no fluxo de comércio internacional. CARBAUCH (2003) cita um exemplo em que a proteção dos golfinhos e das tartarugas marinhas defendida pelos Estados Unidos causa um conflito com as metas de livre comércio da OMC. Pois proteger essas criaturas significa modificar os métodos de pesca do camarão e do atum dos países que utilizam os métodos de pesca que capturam e matam cerca de 150 mil tartarugas marinhas a cada ano, o que gera uma redução na produção e uma queda no fluxo de comércio do camarão e do atum.

\subsubsection{Convenção da Basiléia}

A Convenção de Basiléia controla Movimentos transfronteiriços de Resíduos perigosos e sua eliminação foi ratificada em 1993. Partes desta Convenção conscientiza a respeito dos prejuízos causados à saúde humana e ao ambiente através de resíduos perigosos e 
outros resíduos ${ }^{14}$ e pelos seus movimentos transfronteiriços ${ }^{15}$. A convenção alerta que a maneira mais eficaz de proteger a saúde humana e o ambiente de perigos causados por esses Resíduos é reduzir a sua produção ao mínimo, em termos de quantidade e ou potencial de perigo.

A convenção trata de forma convicta de que os Estados devem tomar as medidas cabíveis para garantir a gestão de Resíduos perigosos e outros Resíduos incluindo o movimento transfronteiriço, assegurando que o produtor se responsabilize pelo transporte e eliminação destes Resíduos de acordo com a proteção do ambiente, qualquer que seja o local da eliminação. Sabendo-se que qualquer Estado tem o direito soberano de proibir a entrada ou eliminação de Resíduos perigosos estrangeiros e outros Resíduos no seu território; Além do crescente desejo de proibir os movimentos transfronteiriços de Resíduos perigosos e a sua eliminação noutros Estados, sobretudo nos países em desenvolvimento. Assim, os Estados devem tomar medidas para o intercâmbio apropriado de informação e controle do movimento transfronteiriço de resíduos perigosos e de outros Resíduos.

As Partes da convenção preocupadas com o problema do tráfego transfronteiriço ilícito de resíduos perigos e outros Resíduos, considerando as capacidades limitadas dos países em desenvolvimento na gestão de resíduos perigosos e de outros resíduos, reconhece, desta forma, a necessidade de promover a transferência de tecnologia relativa à gestão segura dos transportes de resíduos perigosos, principalmente nos países em desenvolvimento (CONAMA, 2011).

A Convenção da Basiléia tem o objetivo de reduzir o movimento transfronteiriço de resíduos perigosos e outros resíduos, desta maneira, pode ocasionar uma redução no fluxo de comércio internacional devido maior rigor dos países importadores, aumento dos custos do produtor-exportador com o transporte dos produtos de um país para outro, assim, há um transporte mais seguro e com menores riscos a saúde humana e ao meio ambiente.

\subsection{A Conferência da OMC em Doha}

Em 2001, na IV Conferência Ministerial, a agenda de desenvolvimento de Doha da OMC apontava vários objetivos que deveriam ser atingidos até 2005 , através da rodada global de conversações comerciais. Os objetivos foram os seguintes: compatibilização dos acordos ambientais multilaterais e as regras da OMC relativas ao Comércio; a eliminação de subsídios à exportação de produtos agrícolas em países desenvolvidos prejudiciais ao ambiente; o desenvolvimento de comércio e ambiente de apóio mútuo; o recurso a rótulos ecológicos; a liberalização de serviços e produtos ambientais.

Em 2003, ocorreu a Conferência de Cancun, a V Conferência Ministerial, que reuniu vários membros da OMC, esta mostrou que ainda há muito a se fazer sobre essas questões, apesar da Declaração de Joanesburgo e da Declaração do Milênio das Nações Unidas.

Conforme Almeida e Dutra (2011), na rodada de negociações de Doha as questões ambientais foram inseridas, principalmente, pela pressão da Comunidade Européia. Os países desenvolvidos receiam que as negociações ambientais possam restringir o acesso a mercados de seus produtos, através das medidas restritivas de comércio com propósitos ambientais. Em

\footnotetext{
${ }^{14}$ Conforme o artigo $2^{\circ}$ da Convenção da Basiléia Resíduos são substâncias ou objetos que são eliminados ou se projeta, ou são objeto de pedido para serem eliminados, de acordo com as cláusulas da lei nacional.

${ }^{15}$ Conforme o artigo $2^{\circ}$ da convenção da Basiléia Movimento transfronteiriço significa qualquer movimento de resíduos, perigosos ou de outros resíduos, de uma área abrangida pela jurisdição nacional de um Estado para, ou através de uma área abrangida pela jurisdição nacional de outro Estado ou para ou através de uma área não abrangida pela jurisdição nacional de qualquer Estado, estando pelo menos dois Estados envolvidos no movimento.
}

REUNIR - Revista de Administração, Contabilidade e Sustentabilidade - Vol. 1, nº 2, p.34-51, Set-Dez/2011. 
relação aos produtos agrícolas, com o apóio americano, eles se preocupam com a restrição do mercado para os produtos derivados dos organismos geneticamente modificados (OGMs) ou também denominados transgênicos, através da rotulagem ambiental, ou da utilização do princípio da precaução, sob o aval dos Acordos sobre Barreiras Técnicas ao Comércio e Medidas Sanitárias e Fitossanitárias da OMC.

A Declaração Ministerial de Doha (DMD) se refere às questões ambientais de forma bastante restrita, deixando de lado os pontos mais polêmicos do seu mandato negociador, restringindo, desta forma, as negociações. Os parágrafos de Doha têm um caráter não negociador em relação às questões ambientais e instrui e encarrega ao Comitê sobre Comércio e Meio Ambiente (CTE) a continuar seus trabalhos sobre o mandato não negociador.

A hierarquia entre os acordos multilaterais e as regras da OMC ficou de fora da reunião em Cancun, pois que a Comunidade Européia (CE) centrou suas atenções em outras questões. Almeida e Dutra (2011) mostram que antes de Cancun, o Canadá sugeriu que os itens do programa de trabalho do CTE pudessem ser revistos, com o intuito de verificar se tais itens ainda são de interesse dos membros. A recomendação não foi acatada e os itens discutidos no CTE continuam os mesmos listados no parágrafo 32 da Declaração Ministerial de Doha (DMD). Sobre a questão de acesso a mercado, esta discussão foi separada em duas partes: primeiro como o efeito de políticas ambientais sobre o mercado e, em segundo, como a eliminação ou diminuição das restrições e distorções ao comércio irão beneficiar o comércio, o meio ambiente e o desenvolvimento.

O efeito das medidas ambientais no acesso a mercados preocupa os países em desenvolvimento pelos possíveis efeitos protecionistas. É direito dos países estabelecerem o nível desejado de proteção ambiental, contanto que esteja de acordo com as regras da OMC. Em relação à segunda parte do parágrafo 32 (i) de Doha, os setores da agricultura, energia, pesca e florestal têm sido discutidos com bastante atenção. De acordo com alguns países membros, uma maior liberalização do comércio nesses setores pode gerar ganhos para o meio ambiente e para o desenvolvimento (OMC, 2011).

O parágrafo 32(iii) da Declaração Ministerial de Doha discute a questão da rotulagem ambiental. O tema vem sendo investigado por governos, indústrias e ONGs. A rotulagem ambiental garante que o produto foi produzido de forma a não agredir o meio ambiente. Com o objetivo de informar ao consumidor como o produto foi produzido.

\subsection{Principais Argumentos para Explicar como a Liberalização Comercial Pode Prejudicar o Meio Ambiente}

Em Carbaugh (2003) argumenta que a liberalização do comércio gerará a transferência das indústrias de produtos dependentes do ambiente ou altamente poluídos para países com padrões ambientais reduzidos. A liberalização comercial poderá até tornar mais vantajosa a mudança de indústrias com chaminés para locais onde a poluição seja aceita. Indústrias com chaminés criam a poluição com efeitos adversos globais, logo a liberalização do comércio pode, indiretamente, promover a degradação ambiental. Além, a pressão competitiva induzida pelo comércio pode forçar os países a uma redução de seus padrões ambientais, gerando o intercâmbio de produtos que criam a poluição ambiental.

Os padrões ambientais de muitas nações industrializadas parecem ser mais severos. Nações em desenvolvimento como o México, a Coréia do Sul, o Brasil e Taiwan têm sido criticadas pelos seus padrões ambientais tolerantes que incentivam a produção de bens fabricados à custa de muita poluição. Entretanto, a maioria das nações industrializadas polui mais que os países em desenvolvimento.

REUNIR - Revista de Administração, Contabilidade e Sustentabilidade - Vol. 1, nº 2, p.34-51, Set-Dez/2011. 
Carbaugh (2003) cita que a relação entre os ambientalistas e a OMC se afetou quando a organização decidiu contra uma proibição dos Estados Unidos que prejudicou as importações de camarão originadas de países que utilizavam redes que apanhavam tartarugas, ao receber reclamações da Índia, da Malásia, do Paquistão e da Tailândia. Os Estados Unidos foram considerados igualmente culpados de violar as leis de comércio internacional quando proibiram a importação de atum mexicano pescado de uma forma que afogava os golfinhos. As políticas de livre-comércio da OMC estavam contrarias as metas de qualidade ambiental.

Outro argumento é que a liberalização do intercâmbio entre os países incentiva o comércio de produtos que criam poluição global. A Liberalização Acelerada de Tarifas, proposta pelos Estados Unidos e alguns outros participantes da OMC em 1999, significa eliminação das tarifas incidentes sobre a madeira e outros produtos correlatos até 2004.

Qualquer medida que liberalize o comércio aumenta a produtividade e o crescimento, reduz a pressão sobre a inflação aumentando a concorrência e o emprego. Países como Japão e China impediram a entrada da maior parte das importações de madeira através de tarifas elevadas em cerca de $40 \%$, as empresas americanas não possuem mercado de madeira acabada. No Japão, os preços elevados limitam a demanda interna no país. Se as tarifas Japonesas fossem abolidas, a demanda por madeiras americanas iriam aumentar, gerando empregos adicionais no setor madeireiro americano e empregos adicionais no Japão relacionados às importações (CARBAUGH, 2003).

Os custos para as empresas atenderem a regulamentação ambiental representam, muitas vezes, uma pequena fração dos custos totais de produção, por isso é improvável que esse fator seja motivo para decisões envolvendo transferências de local. O Censo dos Estados Unidos acredita que mesmo as indústrias mais poluidoras não gastam mais de $2 \%$ de suas receitas para reduzir a poluição. Entretanto, nenhum governo está se apressando para rebaixar os padrões ambientais (CARBAUGH, 2003).

\section{CONSIDERAÇÕES FINAIS}

O panorama industrial-tecnológico internacional atual é intensivo no uso de energia e matéria-prima, causando o aumento das emissões de gases capazes de provocar alterações climáticas e destruição da camada de ozônio, dentre outras conseqüências. A partir disso, a comunidade internacional passou a levar em consideração a necessidade de um controle mais efetivo em relação às questões ambientais.

Para a preservação e a conservação do bem de uso comum da humanidade, o meio ambiente, faz-se necessário o uso de políticas ambientais protecionistas através dos instrumentos ambientais cabíveis. Porém, qual o impacto dessas medidas sobre os fluxos de comércio internacional?

As políticas ambientais de diferentes países podem influenciar nos fluxos de comércio internacional. Quando o produto ou o seu método e processo de produção causam problemas, o país importador pode colocar barreiras ao comércio. São as conhecidas barreiras nãotarifárias ambientais, as barreiras verdes, que restringem o comércio internacional com o objetivo de proteger o meio ambiente.

As barreiras não-tarifárias têm como base requisitos técnicos, sanitários, ambientais, laborais, restrições quantitativas (quotas e contingenciamento de importação), assim como políticas de valoração aduaneira, de preços mínimos e de bandas de preços. Na atualidade, as BNTs funcionam como mecanismo de proteção aos mercados. Essas barreiras afetam as exportações de países em desenvolvimento, pois estes, geralmente, têm menos capacidade em tecnologia para atender as exigências técnicas de proteção ao meio ambiente.

REUNIR - Revista de Administração, Contabilidade e Sustentabilidade - Vol. 1, nº 2, p.34-51, Set-Dez/2011. 
As exigências ambientais com relação às regras da $\mathrm{OMC}$ surgem com a alternativa de adoção de medidas restritivas ao comércio que utilizem como base o artigo XX do GATT, assim como as regras existentes no TBT e no SPS. Com o intuito de proteger a vida e a saúde humana, animal e vegetal, e cuidar da conservação dos recursos naturais exauríveis.

Um bom exemplo disso, são as notificações enviadas ao OMC dentro das bases do TBT, MACHADO (2003) considera que elas possam ser uma proxy da participação desses países na atividade reguladora técnica internacional. Ainda segundo o autor, a União Européia se caracteriza como o país que mais está se valendo do TBT para adotar medidas para proteger o meio-ambiente.

Entretanto, as medidas adotadas com base nas BNTs não devem servir como uma forma de discriminação arbitrária ou injustificável, evitando que se transforme em uma forma de neoprotecionismo. Os países têm direito de estabelecer o nível desejado de proteção ambiental, contanto que esteja de acordo com as regras da OMC. O CTE tem a seu cargo a compatibilização das regras do comércio mundial e os instrumentos de proteção ambiental, por exemplo, os acordos ambientais multilaterais, os esquemas de rótulos ecológicos e o princípio da precaução.

Os defensores do livre-comércio temem que as regras ambientais possam ser utilizadas como justificativa para o protecionismo de países desenvolvidos e que prejudiquem os em desenvolvimento, através de medidas restritivas ao comércio.

\section{REFERÊNCIAS}

ALMEIDA, Luciana Togeiro, DUTRA, Paula Hebling e colaboração de D'ANCORA, Mauro. Comércio e Meio Ambiente. Disponível em:<www.eco.unicamp.br/aspscripts/boletim_ceri/.../07-lucianapaula.pdf > Acesso em 02 out. 2011. Link

ABREU, Isabel. Comércio e Ambiente. Disponível em:< http://naturlink.sapo.pt/article. aspx?menuid=6\&cid=35657\&bl=1>. Acesso em 02 out. 2011. $\underline{\text { Link }}$

BRASIL. Presidência da República. Comissão Interministerial para Preparação da conferência das Nações Unidas sobre Meio Ambiente e Desenvolvimento. O desafio do desenvolvimento sustentável pref. do Presidente Fernando Collor. Brasília: Cima, 1991.

CARBAUGH, Robert. Economia Internacional. Ed. Thompson, 2003.

CITES. Convenção sobre o Comércio Internacional de Espécies da Flora e Fauna Selvagens em Perigo de Extinção. Disponível em: 〈http://www.ibama.gov.br/flora/convecao.htm.>. Acesso em: 03 out.2011. Link

CONAMA. Manual do Cadastro Técnico Federal. Resolução CONAMA $n^{\circ} 23$, de 12 de dezembro de $1996 . \quad$ Disponível em:<http://www.ibama.gov.br/cadastro/manual/html/043600.htm.> Acesso em: 02 out. 2011. Link

GARAY e B.Dias (orgs). Conservação da Biodiversidade. São Paulo: Vozes, 2001. 
GIL, Antônio Carlos. Técnicas de Pesquisa em Economia. 2. ed. Atlas. São Paulo: 1990

GREENPEACE. Companhia Energia. Disponível em:<http://www.greenpeace.org.br/clima/pdf/protocolo_kyoto.pdf.> Acesso em: 03 out. 2011. Link

Instituto Nacional de Metrologia, Normalização e Qualidade Industrial - Inmetro. Coordenação de Articulação Internacional do Inmetro - Manual de Barreiras Técnicas as Exportações. Disponível em: <http://www.inmetro.gov.br/barreirastecnicas/Manual_BarrTecnicas.pdf>. Acesso em: 01 out. 2011. Link

Ministério do Meio Ambiente. OMC e Meio Ambiente. Disponível em: http://www.mma.gov.br. Acesso em: 28 ago.2011. Link

MACHADO, R. Q. As Questões Ambientais no Contexto do Acordo de Barreiras Técnicas ao Comércio (TBT). Monografia. Esalq, São Paulo, 2003.

MAY, Peter H. et. al. Economia do Meio Ambiente: teoria e prática. Rio de Janeiro: elsevier. 2003.

OMC. Organização Mundial do Comércio. Rodada de Doha. Disponível em: < http://www.wto.org/english/tratop_e/envir_e/cte_doha_e.htm.>. Acesso em: 03 out. 2011. $\underline{\text { Link }}$

OMC. Organização Mundial do Comércio. Disponível em: < http://www.wto.org/english/tratop_e/envir_e/envir_e.htm.>. Acesso em: 03 out. 2011. Link

PNUMA - Programa das Nações Unidas para o Meio Ambiente. Protocolo de Montreal relativo às Substâncias que afetam a Camada de Ozônio. Kenya-ONU. Disponível em:< http://ozone.unep.org/pdfs/Montreal-Protocol2000.pdf.> Acesso em: 02 out. 2011. Link

TOMMASI, Luiz Roberto. Estudo de Impacto Ambiental. São Paulo: CETESB. 1993.

ZANELLA, Liane Carly Hermes. Metodologia de estudo e de pesquisa em administração. Florianópolis: Departamento de Ciências da Administração/ UFSC; Brasília. Capes: UAB. 2009. 